\title{
SYNOVECTOMY OF THE ELBOW IN RHEUMATOID ARTHRITIS
}

\author{
THE PLACE OF EXCISION OF THE HEAD OF THE RADIUS \\ S. A. COPELAND. J. G. TAYLOR \\ From the Orthopaedic Department, Norfolk and Norwich Hospital
}

\begin{abstract}
The results of thirty synovectomies of the elbow for rheumatoid arthritis are reported. Satisfactory relief of pain was obtained in twenty-seven elbows and the range of movement was improved in twenty-one. The classical operation includes excision of the radial head but in this series approximately half the radial heads were conserved with comparable results. The results of synovectomy do not significantly deteriorate with time up to ten years and the operation can be done with good results, especially in respect of relief of pain, even in elbows with relatively advanced rheumatoid disease. Radiographic assessment is not of much help in evaluating the results of the operation, but is essential in selection of elbows for synovectomy.
\end{abstract}

In rheumatoid arthritis, if the elbow is severely affected it may compromise the upper limb as a whole by pain, stiffness or instability. Synovectomy of the elbow has long been recognised as a satisfactory procedure. particularly for relief of pain (Allison and Coonse 1929: Swett 1929; Smith-Petersen. Aufranc and Larson 1943).

The operation has been practised with increasing frequency during the past twenty years and a number of reports have been published. Laine and Vainio's (1969) short-term follow-up gave encouraging results and these were confirmed in a longer term study by Porter. Richardson and Vainio (1974). Smaller series with varying operative techniques but similar results have been done by Wilkinson and Lowry (1965). Anderson and Heppenstall (1971). Inglis, Ranawat and Straub (1971), Peterson and Jones (1971). Wilson (1971) and Marmor (1972).

None of these reports has evaluated whether preservation, as opposed to excision, of the head of the radius affects the outcome of the operation.

This paper describes the experience over a period of ten years of synovectomy of the elbow in which approximately half of the operations included preservation of the radial head. All the operations were performed by one surgeon (J. G. T.) and independently reviewed by another (S. A. C.).

\section{CLINICAL MATERIAL}

Thirty synovectomies of the elbow, all for rheumatoid disease, were done at Norfolk and Norwich Hospital between 1968 and 1976.

There were twenty-five patients, twelve males and thirteen females, with an average age of fifty-five years (range fourteen to sixty-six years). Five patients had bilateral synovectomies. The average duration of the rheumatoid disease was 12.7 years (range two to twenty-five years) and follow-up after operation averaged four years three months (range one to ten years). All patients had had a full trial of medical treatment. Twelve patients were on steroids or had received them within the year before the operation. In only five patients was the elbow the sole severely affected joint. The hand of the same arm was involved in nineteen patients, the wrist in sixteen, the shoulder in eleven and all three joints in six patients. Seven patients had had previous operations: three dorsal synovectomies of the wrist, one metacarpophalangeal synovectomy, one excision of the ulnar head, one decompression of the carpal tunnel and in one patient the tendon of extensor pollicis longus had been repaired.

The indications for the operation were pain with or without persistently active rheumatoid synovitis not responding to medical treatment. Elbows which were very stiff were not accepted for synovectomy, nor were those with radiographic appearances of advanced erosion of bone with incongruity of the humero-ulnar joint.

\section{METHOD OF STUDY}

All patients were asked to attend for review. Seventeen patients with twenty synovectomies were seen and examined personally and radiographs were taken.

Five patients could not attend, three because they had moved out of the area and two because of illness. These patients were sent a questionnaire and their clinical records and radiographs were studied. Three patients who had died were included in the series. Their five

S. A. Copeland, F.R.C.S., Senior Registrar, St Bartholomew's Hospital, West Smithfield. London EC1A 7BE. England.

J. G. Taylor, F.R.C.S., Consultant Orthopaedic Surgeon, Norfolk and Norwich Hospital, St Stephen`s Road, Norwich. Norfolk, England.

Requests for reprints should be sent to Mr J. G. Taylor. 
synovectomies were assessed from their clinical records, which had been well maintained. The assessment of these eight patients who were not personally seen did not affect the balance of the results.

Assessment of results of the operation was on a simple basis of satisfactory or unsatisfactory on the clinical criteria used by Porter $e t$ al. (1974): Table I. Radiographic assessment was not used as a criterion in this series since a satisfactory clinical result may continue despite deterioration that is apparent in radiographs.

Table I. Criteria for assessing success of synovectomy of the elbow

\begin{tabular}{|l|l|}
\hline \multicolumn{1}{|c|}{ Satisfactory } & \multicolumn{1}{c|}{ Unsatisfactory } \\
\hline Patient pleased & $\begin{array}{l}\text { Patient dissatisfied or } \\
\text { uncertain }\end{array}$ \\
Good relief of pain & $\begin{array}{l}\text { Pain: same, worse or } \\
\text { only slightly better } \\
\text { Unstable joint }\end{array}$ \\
$\begin{array}{l}\text { No symptomatic instability } \\
\text { Range of movement not less } \\
\text { than } 30 \text { to } 130 \text { degrees }\end{array}$ & Loss of movement \\
\hline
\end{tabular}

The patients were asked whether they considered that the pain, movement and function of their elbows were better, the same or worse than before the operation. The surgeon's assessment was made on relief of pain, and on stability, range of movement and recurrence of active synovitis.

\section{OPERATIVE TECHNIQUES}

The bilateral approach was used for twenty-two operations. In the other eight elbows the approach was unilateral only. The other variables were preservation of the radial head and transposition of the ulnar nerve; these variations are all shown in Table II.

The lateral approach was used in some of the earlier cases: this technique gives good access to the front of the joint and to the back of

Table II. Variations in the operation performed

\begin{tabular}{|llr|}
\hline Approach & Bilateral & 22 \\
& Lateral & 7 \\
& Medial & 1 \\
\hline Radial head & Removed & 16 \\
& Preserved & 14 \\
\hline Ulnar nerve & Transposed & 22 \\
& Not transposed & 8 \\
\hline
\end{tabular}

the olecranon fossa but it does not give access to the medial side of the joint and the ulnar nerve. A medial approach alone was used once because of predominant ulnar nerve symptoms.

In the majority of patients a bilateral approach was used, the anterior synovectomy being conducted from the lateral side and the medial and posterior synovectomy from the ulnar side. This approach also facilitated inspection of the ulnar nerve, which was transposed anteriorly and subcutaneously in all except one elbow where it did not appear to be involved in the rheumatoid process.

It has been found that with this bilateral technique it is not necessary to remove the head of the radius for access alone and thus the radial head was preserved if it still retained some articular cartilage and was congruous with the capitulum.

Suction drainage was used in all the operations. A plaster-of-Paris back slab was applied for five to seven days at which time the wound was inspected and, if satisfactory, active mobilisation of the elbow began.

\section{RESULTS}

Pain. The indications for synovectomy of the elbow had been pain and an active rheumatoid synovitis. Figure 1 shows how the surviving patients described the pain before and after operation. No patient's pain was made worse, and twenty-two out of twenty-five elbows had little or none. Scrutiny of the notes of the three deceased patients indicated that of the five elbows, all severely painful before operation, there had been complete relief of pain in four and moderate relief in one.

Range of movements. The observed range of movement was increased in twenty-two of the thirty elbows. The deceased patients were included, their range of movement having been taken from the most recent recordings in the clinical notes. A few patients, however, stated that

Table III. Range of movements after operation

\begin{tabular}{|l|c|c|c|}
\hline \multirow{2}{*}{\multicolumn{1}{|c|}{ Movement }} & \multicolumn{3}{|c|}{ Assessment } \\
\cline { 2 - 4 } & Better & Same & Worse \\
\hline Flexion and extension & 22 & 7 & 1 \\
Pronation & 18 & 7 & 5 \\
Supination & 14 & 13 & 3 \\
\hline
\end{tabular}

their range of movements increased when in fact it had remained the same. This is a common finding in the assessment of rheumatoid surgery because the patient has been given movement that he can use free of pain. The results are shown in Table III.

The average range of flexion and extension before operation was 35 to 125 degrees (ranges 90 to 120 degrees and 10 to 150 degrees), average pronation 55 degrees (range 10 to 90 degrees) and average supination 60 degrees (range 0 to 90 degrees). The improvement after operation is shown in Figures 2 and 3.

In those patients with some loss of movement of rotation the majority lost a little pronation which can be masked at the shoulder.

Function and stability. Twenty-two surviving patients with twenty-five synovectomies of the elbow considered twenty-two of these operations to have improved their function. Two patients considered their elbows to be the same and one worse.

Stability of all elbows was tested at review but in none could any symptom be attributed to instability, although this was difficult to test as all had varying degrees of fixed flexion deformity from 10 to 55 degrees. 
In one elbow the radius was seen to subluxate anteriorly on pronation; the lower end of ulna had been excised at a previous operation and the head of radius excised at the time of synovectomy. This subluxation did not cause the patient any pain or inconvenience.

Deterioration and further operations. Two patients deteriorated and had to have further operations. At the first operation on one patient the radial head was conserved and because of predominant ulnar nerve

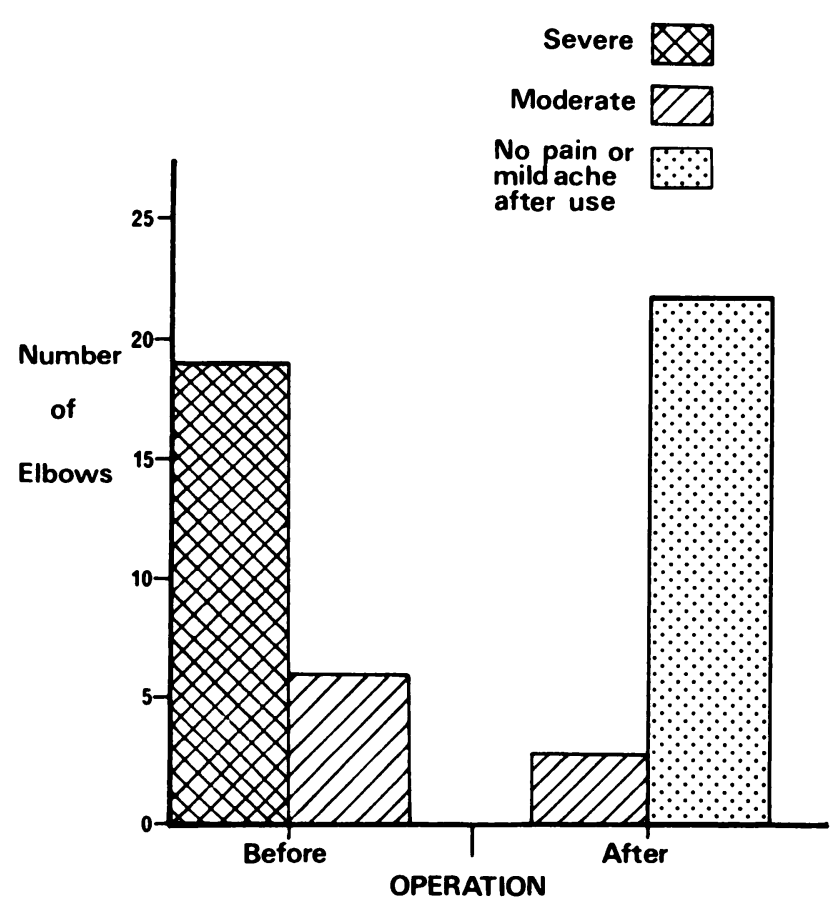

Fig. 1

Patients' assessment of pain.

symptoms synovectomy was by the medial approach only. This treatment did not relieve her pain. One year after the first operation, a bilateral approach for re-synovectomy and excision of the radial head gave complete relief of symptoms. Because of the failure of the first operation and despite the successful outcome of the second, she is nevertheless included in the unsatisfactory results.

The other patient, who had had the radial head conserved at the time of synovectomy, continued to complain of pain after operation. Radiographs showed rapid deterioration and the head of the radius became almost ankylosed to the capitulum. At re-operation the radial head was removed with only partial relief of pain.

There were no wound infections.

Radiographic assessment at review. Radiographic changes were assessed on a scale based on that of Steinbrocker, Traeger and Batterman (1949): Grade 0 -normal joint; Grade I-osteoporosis and soft-tissue changes only; Grade II-mild or moderate degree of erosive changes, mild or moderate reduction of "joint space"; Grade III - joint space markedly narrowed (to
0 to 1 millimetre) and more extensive erosions; Grade IV-subluxation or ankylosis. Table IV shows the distribution of the cases in the present series. However, this radiographic grading was so often at variance with the clinical result that it was not acceptable as a valid criterion in the overall assessment of the operation.

Table IV. Radiographic grading

\begin{tabular}{|r|c|}
\hline Grade & Number of elbows \\
\hline 0 & 0 \\
I & 0 \\
II & 8 \\
III & 21 \\
IV & 1 \\
\hline
\end{tabular}

Overall assessment. Patients' assessment. Twenty-three patients were satisfied with twenty-eight operations. This includes the records of the three deceased patients, who had expressed satisfaction with all five of their synovectomies; three of these were at four years follow-up, one at one year and one at two years.

Two patients were dissatisfied. One of these, mentioned previously, had had to have the radial head

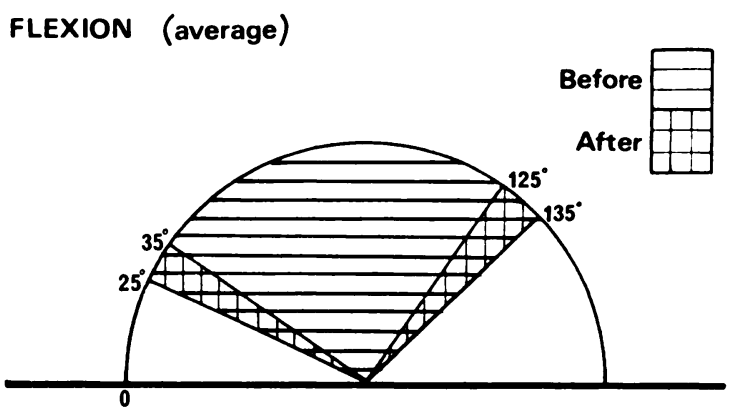

Fig. 2

\section{SUPINATION}

PRONATION (average)

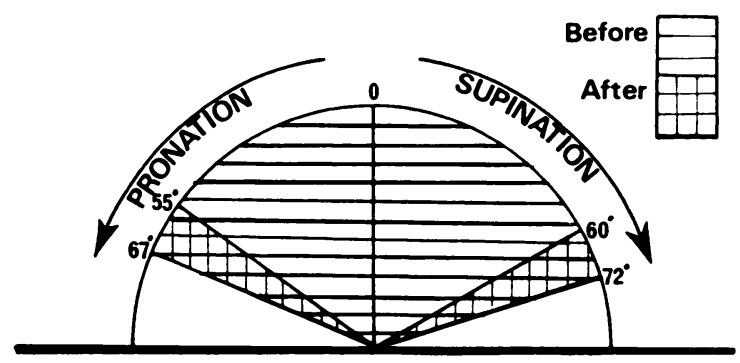

Fig. 3

Figure 2-Average range of flexion before and after operation. Figure 3-Average range of supination and pronation before and after operation. 
excised at a second operation with incomplete relief of pain and no improvement in function or range of movement. The other patient would not attend for review and considered the pain, function and movement of her elbow to be unchanged.

Surgeon's assessment. In the surgeon's assessment twenty-four elbows were considered to be satisfactory and six unsatisfactory.

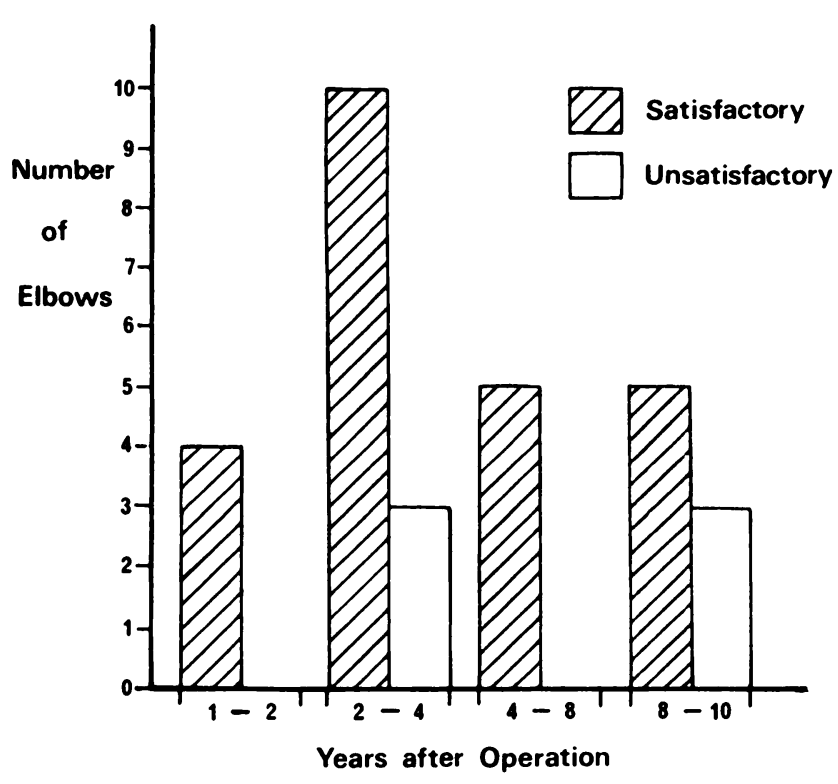

Fig. 4

Success related to time since operation.

Of the six failures, three were because the range of movements was either less than before operation or insufficiently improved to fulfil the "satisfactory" criterion of 30 to 130 degrees; two of these patients also had inadequate relief of pain. Two elbows were considered to be unstable, although one was considered a satisfactory result because the instability was asymptomatic; the other elbow had been grossly destroyed and unstable before operation, and in retrospect the patient would have perhaps been better with an arthroplasty although her pain was partly relieved. One elbow was a failure because it required a second operation although at follow-up it fulfilled all the satisfactory criteria. The sixth patient was the one referred to above who would not attend for review. She considered her elbow to be no better than before operation, and the reason for failure could not be ascertained.

Peripheral nerve assessment. None of the patients complained of any sensory dysfunction but on examination five patients were found to have a mild sensory deficit in the distribution of the ulnar nerve. All these patients had had the bilateral approach and the ulnar nerve had been transposed. Because of severe rheumatoid changes in the hands of many patients, it was impossible to assess the motor function accurately.

\section{DISCUSSION}

A higher proportion of satisfactory results was obtained using a bilateral approach (Table V). It is considered that the best access is obtained by this approach. It would seem unnecessary to consider the transolecranon approach described by Inglis et al. (1971). The complications of non-union and breaking of the screw are thus avoided.

Table V. Success related to operative approach

\begin{tabular}{|l|c|c|c|}
\hline \multirow{2}{*}{ Approach } & \multirow{2}{*}{$\begin{array}{c}\text { Number of } \\
\text { operations }\end{array}$} & \multicolumn{2}{|c|}{ Results } \\
\cline { 3 - 4 } & 22 & 19 & 3 \\
\hline Bilateral & 7 & 5 & 2 \\
Lateral & 1 & 0 & 1 \\
Medial & 22 Unsatisfactory \\
\hline
\end{tabular}

The radial head must contribute to the stability of the elbow and wrist. Taylor and O'Connor (1964) showed in their series that excision of the radial head after a comminuted fracture led to half of the patients developing painful subluxation of the inferior radioulnar joint. It would therefore seem desirable to conserve the radial head in the rheumatoid elbow if its condition did not demand removal. This series shows that good results of elbow synovectomy may be obtained while conserving the radial head (Table VI).

Table VI. Success related to excision of the radial head

\begin{tabular}{|l|c|c|c|}
\hline & Number & Satisfactory & Unsatisfactory \\
\hline Radial head conserved & 14 & 11 & 3 \\
Radial head excised & 16 & 13 & 3 \\
\hline
\end{tabular}

Success related to time since operation is shown in Figure 4. There does not appear to be deterioration of results with time up to eight years, and possibly ten years, follow-up. The higher proportion of failure in the eight to ten years group is because two of these were failures from the outset, due to faulty selection in the earlier operations. 


\section{REFERENCES}

Allison, N., and Coonse, G. K. (1929) Synovectomy in chronic arthritis. Archives of Surgery, 18, 824-840.

Anderson, L. D., and Heppenstall, M. (1971) Synovectomy of the elbow and excision of the radial head in rheumatoid arthritis. In Surgery of Rheumatoid Arthritis, pp. 127-134. Edited by R. L. Cruess and N. S. Mitchell. Philadelphia and Toronto: J. B. Lippincott Company.

Inglis, A. E., Ranawat, C. S., and Straub, L. R. (1971) Synovectomy and débridement of the elbow in rheumatoid arthritis. Journal of Bonte and Joint Surgery, 53-A, 652-662.

Laine, V., and Vainio, K. (1969) Synovectomy of the elbow. In Early Synovectomy in Rhe'umatoid Arthritis, pp. $117-118$. Edited by W. Hijnans. W. D. Paul and H. Hershel. Amsterdam: Excerpta Medica Foundation.

Marmor, L. (1972) Surgery of the rheumatoid elbow. Journal of Bone and Joint Surgery, 54-A, 573-578.

Peterson, L. F. A., and Jones, J. M. (1971) Surgery of the rheumatoid elbow. Orthopedic Clinics of North America. 2, 667-677.

Porter, B. B., Richardson, C., and Vainio, K. (1974) Rheumatoid arthritis of the elbow: the results of synovectomy. Journal of Bone and Joint Surgery, 56-B, 427-437.

Smith-Petersen, M. N., Aufranc, O. E., and Larson, C. B. (1943) Useful surgical procedures for rheumatoid arthritis involving joints of the upper extremity. Archives of Surgery, 46, 764-770.

Steinbrocker, O., Traeger, C. H., and Batterman, R. C. (1949) Therapeutic criteria in rheumatoid arthritis. Journal of the' American .1/'(lical Association, 140, 659-662.

Swett, P. P. (1929) The present status of synovectomy. American Journal of Surgery. N.S. 6, 807-810)

Taylor, T. K. F., and O'Connor, B. T. (1964) The effect upon the inferior radio-ulnar joint of excision of the head of the radius in adults. Journal of Bone and Joint Surgerv, 46-B, 83-88.

Wilkinson, M. C., and Lowry, J. H. (1965) Synovectomy for rheumatoid arthritis. Journal of Bone and Joint Surgery, 47-B, 482-488.

Wilson, D. W. (1971) Synovectomy of the elhow for rheumatoid arthritis. Proceedings of the Royal Society of Medicine. 64, 264-266. 